\title{
"STUDI EKSPERIMENTAL GASIFIKASI UPDRAFT SEKAM PADI DAN BATUBARA UNTUK PRODUKSI GAS MAMPU BAKAR ”
}

\author{
Akhmad Syarief ${ }^{1)}$, Yopi Riyanto ${ }^{2)}$ \\ 1,2Program Studi Teknik Mesin, \\ Fakultas Teknik Universitas Lambung Mangkurat \\ Jl. Ahmad Yani KM 38 Banjarbaru, Kalimantan Selatan, 70714 \\ Telpon. 0511-4772642, Fax 0511-4772642 \\ E-mail : yopiriyanto45@gmail.com
}

\begin{abstract}
Abstrak. Penelitian ini bertujuan untuk mengetahui jumlah syngas yang dihasilkan pada proses gasifikasi pencampuran sekam padi dengan batubara kualitas rendah pada temperatur $500{ }^{\circ} \mathrm{C}$ dan mengetahui jumlah pruduk sampingan berupa Tar dan Char dari proses gasifikasi updraft sekam padi dan batubara kualitas rendah pada temperatur $500{ }^{\circ} \mathrm{C}$. Pada penelitian ini didapatkan hasil syngas pada proses gasifikasi updraft sekam padi dan batubara kualitas rendah yaitu sebanyak 96,62 L. Volume terbanyak pada sempel SP $200 \mathrm{gr}$ : BB 0 gr sebesar sebesar 29,56 L, pada sempel SP $180 \mathrm{gr}$ : BB $20 \mathrm{gr}$ sebesar 25,7 L, pada SP $140 \mathrm{gr}$ : BB $60 \mathrm{gr}$ sebesar $21.88 \mathrm{~L}$ dan volume paling sedikit pada SP $100 \mathrm{gr}$ : BB $100 \mathrm{gr}$ sebesar 19.45L. Hasil dari produk sampingan gasifikasi updraft sekam padi dan batubara kualitas rendah didapatkan hasil Tar paling tinggi pada sempel SP $200 \mathrm{gr}: \mathrm{BB} 0 \mathrm{gr}$ sebanyak 58,75 ml, pada sempel SP $180 \mathrm{gr}:$ BB $20 \mathrm{gr}$ dihasilkan sebanyak $45 \mathrm{ml}$, pada sempel SP 140 gr BB $60 \mathrm{gr}$ dihasilkan 32,5 ml dan pada sempel SP $100 \mathrm{gr}:$ BB $100 \mathrm{gr}$ dihasilkan sebanyak 22,5 m.
\end{abstract}

Kata kunci: Gasifikasi, Updraft, Sekam Padi, Batubara.

In this research have a purpose the amount of syngas produced in the process of mixing rice husk gasification with low quality coal at temperature $500^{\circ} \mathrm{C}$ and to know the number of side pruduk of Tar and Char from gasification updraft rice husk and low quality coal at temperature $500{ }^{\circ} \mathrm{C}$. In this research, the result of syngas on updraft gasification process of rice husk and low quality coal is as much as 96,62 L. The highest volume in sempel SP $200 \mathrm{gr}:$ BB 0 gr equal to 29,56 L, at sempel SP 180 gr: $B B 20 \mathrm{gr}$ equal to 25,7 L, at SP $140 \mathrm{gr}: \mathrm{BB} 60 \mathrm{gr}$ equal to $21.88 \mathrm{~L}$ and volume at least on SP 100 gr: $B B 100 \mathrm{gr}$ equal to $19.45 \mathrm{~L}$. The result of by-product of updraft gasification of rice husk and low quality of coal was obtained by highest tar on SP $200 \mathrm{gr}: 0 \mathrm{ml}$ of $58.75 \mathrm{ml}$, at sempel SP $180 \mathrm{gr}:$ BB 20 g produced as much as $45 \mathrm{ml}$, at

SP $140 \mathrm{gr} \mathrm{BB} 60 \mathrm{~g}$ produced 32,5 ml and at sempel SP $100 \mathrm{gr}:$ BB $100 \mathrm{gr}$ yielded as much as 22,5 m

Keywords: Gasification, Updraft, Rice Husk, Coal. 


\section{PENDAHULUAN}

Energi fosil adalah energi yang berasal dari fosil yang menjadi mineral terkubur dibawah bumi jutaan tahun lalu yang menghasilkan gas, batubara dan minyak bumi. Selama ini konsumsi energi fosil di Indonesia masil relatif tinggi sebesar $96 \%$ sektor minyak bumi sebesar $48 \%$, batubara $30 \%$ dan gas 18\%. Daklam hal ini upaya untuk menekan konsumsi energi fosil dengan memafaatkan energi baru terbarukan masih belum berjalan sesuai dengan yang direncanakan. Berdasarkan data badan geologi (2011), batubara kualitas rendah mengandung nilai kalor yang lebih rendah dari batubara jenis lainnya dan kandungan kadar air yang sangat tinggi, hal inilah yang membuat batubara kualitas rendah hanya dimanfaatkan didalam negri untuk kebutuhan listrik tenaga uap (Batubara Indonesia, 2008).Biomassa merupakan sumber energi baru terbarukan yang memiliki potensi yang cukup besar. Bioamassa adalah bahan organik pada energi baru terbarukan, salah satu bahan organik yang mudah ditemukan ialah sekam padi. Sekam padi banyak mudah ditemukan selain itu sekam padi juga masih dijual murah dipasaran Kalimantan Selatan merupakan salah satu provinsi lumbung padi nasional dan menjadi penghasil padi nomor satu di pulau Kalimantan data Badan Pusat Statistik tahun 2016 menunjukkan bahwa produksi padi di Kalimantan Selatan sebesar 2.140.276 ton dengan luas panen 511.213 ha (BPS KALSEL, 2016).

Dari permasalahan diatas maka diperlukan teknologi yang mampu memanfaatkan sekam padi dan batubara untuk dijadikan gas mampu bakar. Teknologi ini disebut dengan gasifikasi yang menghasilkan gas mampu bakar (syngas) dan produk sampingan berupa Tar dan Char

\section{Gasifikasi}

Gasifikasi adalah suatu proses untuk mengubah material padat pada biomassa menjadi bahan bakar gas atau bahan baku gas kimia (syngas) yang sering disebut gasifikasi. (Asian Biomass Handbook, 2018). Pada proses gasifikasi adalah suatu proses untuk mengubah bahan yang mengandung karbon mejadi gas mampu bakar. Gasifikasi memerlukan bahan dasar yang mengandung hidrokarbon seperti biomassa dan batubara. Didalam tungku terjadi proses pemanasan sampai temperatur reaksi tertentu dan selanjutnya proses gasifikasi akan menghasilkan gas mampu bakar dan produk sampingan berupa tar dan char. Pada gasifikasi akan dihasilkan synthetic gas (syngas) dengann komposisi, rasio dan karakteristik gas yang berbeda-beda tergantung pada bahan baku, proses, dan jenis gasifer yang digunakan. (Abdul Ghofar, dkk 2017). Biomassa padatan dapat dirubah menjadi gas mampu bakar, proses ini membutuhkan bahan tambahan untuk mendorong reaksi kimia pada proses gasifikasi. Bahan ini disebut dengan agen gasifikasi, kandungan utama dari bahan ini adalah oksigen, $\mathrm{CO}_{2}$ diaplikasikan pada campuran dan $\mathrm{N}_{2}$. Pada udara hanya oksigen yang mampu bereaksi karena oksigen mampu membangkitkan panas dan meningkatnya oksigen ini akan membantu menurunkan jumlah gas mampu terbakar. (Asian Biomass Handbook, 2008).

\section{Jenis Gasifikasi}

Gasifikasi dibagi menjadi dua berdasarkan arah aliran gasnya, gasifikasi updraft dan gasifikasi downdraft.

\section{a. Updraft Gasification}

Gasifikasi tipe updraft umumnya memiliki ciri khas yaitu pada arah aliran udara dari blower akan masuk melalui bagian bawah tungku. Kemudian gas $\mathrm{N}$ akan masuk melalui bagian bawah tungku untuk mendorong oksigen keluar dari tungku dimana tidak akan terjadi 
proses pembakaran. Gas mampu bakar akan dikeluarkan dari atas tungku. Hasil dari proses yang berupa gas mampu bakar akan keluar dari bagian atas gasifer sedangkan produk sampingan dari proses gasifikasi yang berupa abu akan jatuh ke bagian bawah gasifier karena pengaruh gaya gravitasi dan berat jenis abu, hal ini lah yang menyebabkan kandungan gas mampu bakar menjadi lebih bersih. Gas mampu bakar akan bergerak menuju bagian atas gasifier yang memiliki temperatur lebih rendah. Salah satu keunggulan dari tipe updraft ialah dapat digunakan dalam skala kecil dan arang yang dihasilkan sedikit karena terbawa oleh gas keatas, sedangkan kekurangan dari tipe updraft ialah tar yang dihasilkan lebih banyak.

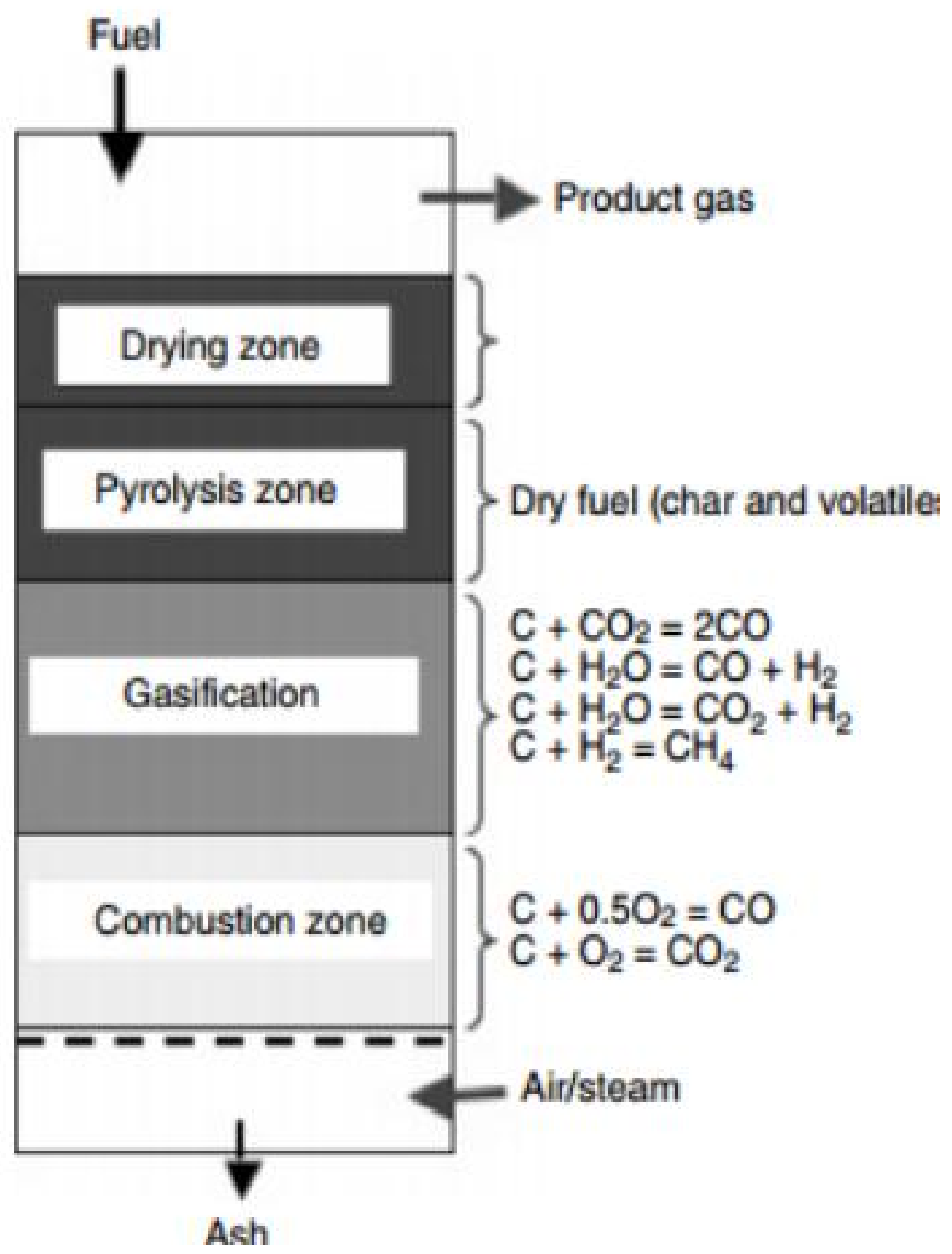

Gambar 1 Skema Gasifikasi updraft 


\section{b. Downdraft Gasification}

Pada gasifikasi downdraft memiliki ciri khusus yaitu arah aliran udara akan masuk melalui bagian atas tungku. Pada gasifikasi tipe ini gas $\mathrm{N}$ masuk melalui bagian atas gasifier untuk mendorong oksigen keluar tungku sehingga tidak akan terjadi proses pembakaran. Sementara produksi gas mampu bakar akan keluar melalui bagian bawah tungku. Kekurangan pada gasifikasi downdraft dimana gas yang dihasilkan kurang bersih dari pada tipe updraft karena kandungan char akan ikut terbawa keluar oleh gas yang terpengaruh gaya gravitasi dan abu yang keluar bersamaan dengan gas akan sulit dikendalikan.

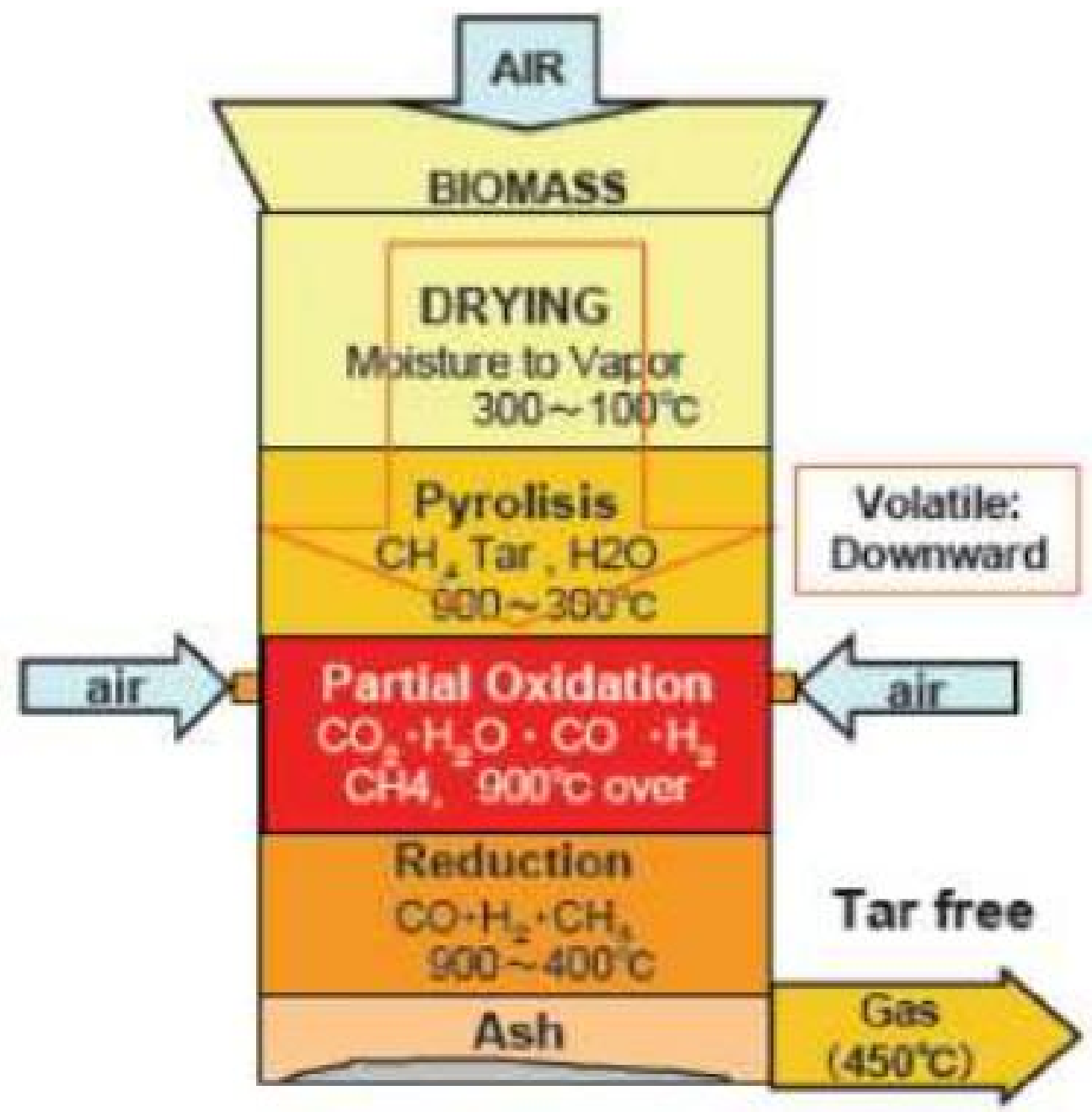

Gambar 2 Skema Downdraft Gasification

\section{Proses-Proses Pada Reaktor Gasifikasi}

Gasifikasi ialah suatu proses dekomposisi zat kimia dengan temperatur tinggi yang dimanfaatkan untuk mendapatkan energi dari hidrokarbon yang membutuhkan proses pembakaran dengan udara yang sangat terbatas. Pada proses gasifikasi dimana molekulmolekul hidrokarbon yang mempunyai rantai panjang dan rumit akan dipecah menjadi molekul yang lebih kecil dan sederhana dalam bentuk gas. Produk sisa dalam proses gasifikasi berupa tar dan arang. Tar didapatkan dari kondesasi gas yang keluar dari tungku, 
sedangkan arang adalah amapas atau sisa dari bahan dasar yang sudah mengalami pembakaran didalam tungku yang tidak berubah menjadi gas. Pada sebagian gas yang didapatkan dari proses gasifikasi akan keluar dari tungku gasifikasi dan masih mengandung air oleh karena itu masih perlu adanya proses kondesasi agar gas yang didapatkan menjadi lebih bersih.

\section{a. Proses Pengeringan}

Pada zona pengeringan biomassa dikeringkan dengan memanfaatkan energi panas dari matahari sebelum biomassa dimasukan kedalam reaktor gasifer. Pada bahan bakar padat terdapat kandungan air, kandungan air ini daat dikurangi dengan memanfaatkan bahan dan udara yang masuk ke dalam tungku. Pada proses pengeringan asam-asam organik akan diuapkan. Temperatur pada zona ini berkisar antara $100-250^{\circ} \mathrm{C}$.

\section{b. Proses Pirolisis}

Proses pirolisis merupakan proses pembakaran tanpa melibatkan oksigen, sehingga terjadi proses pembakaran tidak sempurna. Biomassa akan membentuk gas, tar dan char yang terjadi pada proses pirolisis. Proses pirolisis berlangsung sekitar temperatur $300{ }^{\circ} \mathrm{C}$ pada proses pirolisis produk yang dihasilkan ialah. Biomassa Char $+\operatorname{Tar}+\operatorname{Gas}\left(\mathrm{CO}_{2} ; \mathrm{CO} ; \mathrm{H}_{2} \mathrm{O}\right.$; $\left.\mathrm{H}_{2} ; \mathrm{CH}_{4}\right)$

\section{c. Proses Reduksi}

Kandungan char yang dihasilkan pada proses pirolisis tidak sepenuhnya mengandung karbon, terdapat juga kandungan senyawa kimia seperti hidrogen dan oksigen . Untuk itu, agar dihasilkan gas mampu bakar seperti hidrogen dan karbon monoksida, maka char tersebut harus direaksikan dengan karbon dioksida. Pada proses reduksi terjadi pada temperatur $400^{\circ} \mathrm{C}-1000{ }^{\circ} \mathrm{C}$ dan gas yang dapat terbakar hanya $\mathrm{CO}, \mathrm{H}_{2}$ dan $\mathrm{CH}_{4}$ mulai terbentuk.

\section{d. Proses Oksidasi}

Proses pembakaran akan mengoksidasi kandungan hidrogen dan karbon yang terdapat dalam bahan bakar dengan reaksi eksotermik, sedangkan gas yang dihasilkan dari proses endotermik akan direduksi. Proses pembakaran merupakan proses terpenting dalam gasifer, karena pada proses pembakaran ini akan membentuk energi panas yang dibutuhkan pada reaksi endotermik. Pada proses ini akan dihasilkan panas, cahaya, $\mathrm{N}_{2}$ dan gas lainnya $\left(\mathrm{SO}_{2}, \mathrm{CO}, \mathrm{NO}_{2}\right.$ dan lain-lain). Untuk melakukan reaksi pembakaran, terdapat tiga elemen penting yang saling mengisi satu sama lain yaitu panas (heat), bahan bakar (fuel) dan udara. Proses pembakaran terdiri dari dua jenis yaitu pembakaran tidak sempurna dan pembakaran sempurna. Pembakaran tidak sempurna terjadi apabila unsur $\mathrm{C}$ yang terkandung dalam bahan bereaksi dengan $\mathrm{O}_{2}$ dan gas yang dihasilkan seluruhnya $\mathrm{CO}_{2}$, sedangkan Permbakaran sempurna terjadi apabila seluruh unsur $\mathrm{C}$ yang bereaksi dengan $\mathrm{O}_{2}$ hanya menghasilkan $\mathrm{CO}_{2}$, seluruh unsur $\mathrm{H}$ menghasilkan $\mathrm{H}_{2} \mathrm{O}$ dan seluruh $\mathrm{S}$ menghasilkan $\mathrm{SO}_{2}$. Temperatur pada zona ini berkisar antara $700-1500^{\circ} \mathrm{C}$

\section{Biomassa}

Biomassa merupakan bahan biologis yang berstuktur karbon dan tersusun dari campuran kimiawi yang megandung nitrogren, oksigen, hidrogen dan elemen-elemen lainnya. Biomassa adalah sumber daya yang dapat diperbaharui. Sekam padi jika digunakan sebagai umpan gasifikasi sekam padi memiliki keunggulan karena kadar airnya cukup rendah dan ukurannya seragam. Sekam padi juga memiliki rapat massa yang rendah, yaitu $122 \mathrm{~kg} / \mathrm{m}^{3}$ dan 
rapat massa padatan sebesar $500 \mathrm{~kg} / \mathrm{m}^{3}$. Hasil analisis proksimat dan ultimat untuk sekam padi ditampilkan pada tabel dibawah ini.

Tabel 1 Analisis Proksimat dan ultimat Sekm Padi

\begin{tabular}{|l|l|l|l|}
\hline \multicolumn{2}{|c|}{ Analisa proksimat } & \multicolumn{2}{c|}{ Analisa ulimat } \\
\hline Komponen & \% Massa & \multicolumn{1}{c|}{ Komponen } & \% Massa \\
\hline Volatil & 57.06 & Hidrogen & 5.59 \\
\hline Karbon tetap & 15.58 & Karbon & \\
\hline Abu & 19.52 & Sulfur & 34.92 \\
\hline Air & 7.84 & Nitrogen & 0.08 \\
\hline & & Oksigen & 0.34 \\
\hline & & Abu & 39.55 \\
\hline & & & 19.52 \\
\hline
\end{tabular}

Pada sekam padi terkandung lignin sebesar 23,16\%, selulosa 32,69\% dan hemiselulosa 43,86\% (Eni, 2015). Pada proses gasifiksi sekam padi akan melewati proses pengeringan pada temperatur $60{ }^{\circ} \mathrm{C}-134{ }^{\circ} \mathrm{C}$ sehingga kadar air pada sekam padi akan berkurang. Terjadi dekomposisi pada kandungan struktur kimia pada sekam padi ditahap pertama sampai temperatur mencapai $341{ }^{\circ} \mathrm{C}$, dimana hemiselulosa terdegradasi yang menyebabkan terjadinya uap volatile, sehinnga terputusnya rantai alifatik dan menghilangkan kandungan lilin.

\section{Batubara}

Batubara dikenal sebagai "emas hitam", masyarakat mengenalnya sebagai batu hitam yang bisa terbakar, ahli geokimia batubara, berpendapat batubara merupakan batuan sedimen yang secara kimia dan fisika adalah heterogen yang mengandung unsur-unsur karbon, hidrokarbon, hidrogen, serta oksigen sebagai komponen unsur utama dan belerang serta nitrogen sebagai unsur tambahan. Klasifikasi batubara terdiri dari aspek komersial dan aspek ilmiah. Klasifikasi batubara untuk kepentingan ilmiah antara lain mencakup ganesa batubara dan rank nya, sedangkan untuk kebutuhan komersial antara lain nilai perdangan dan pemanfaatannya. Secara umum klasifikasi batubara di indonesia dibagi menjadi brown coal dan hard coal (SNI 13-6011-1999, 1999). Brown coal (Batubara energi rendah) adalah jenis batubara dengan peringkat paling rendah, bersifat lunak, mudah diremas, mengandung air yang tinggi (10-70\%), dan terdiri atas soft brown coal dan lignitic atau hard brown coal. Nilai kalorinya $<7.000$ kalori/gram (dry ash free-ASTM 388-1984). Hard coal didefinisikan 
sebagai semua jenis batubara yang memiliki peringkat lebih tinggi dari brown coal, bersifat lebih keras, tidak mudah diremas, kompak, mengandung kadar air yang relatif rendah, umumnya struktur kayu tidak tampak lagi, dan relatif tahan terhadap kerusakan fisik pada saat penanganan. Nilai kalorinya > 7.000 kalor/gram (dry ash free-ASTM 388-1984).

Tabel 2 Komposisi elemen dan nilai kalor dari berbagai tipe batubara

\begin{tabular}{|c|c|c|c|c|c|}
\hline \multicolumn{6}{|c|}{ Komposisi Elemen dari Beberapa Tipe Batubara } \\
\hline \multirow[b]{2}{*}{ Jenis Batubara } & \multicolumn{5}{|c|}{ Persentase Massa } \\
\hline & $\% \mathrm{C}$ & $\% \mathbf{H}$ & $\% \mathrm{O}$ & $\% \mathrm{H} 2 \mathrm{O}$ & $\begin{array}{c}\text { Volatile } \\
\text { Metter \% }\end{array}$ \\
\hline Lignit & $60-70$ & $5-6$ & $20-30$ & $50-70$ & $45-55$ \\
\hline Subbituminous & $75-80$ & $5-6$ & $15-20$ & $25-30$ & $40-45$ \\
\hline Bituminous & $80-90$ & $4-5$ & $10-15$ & $5-10$ & $20-40$ \\
\hline Antrasit & $90-955$ & $2-3$ & $2-3$ & $2-5$ & $5-7$ \\
\hline
\end{tabular}




\section{Metode Penelitian}

Pada penelitian ini mengunakan jenis gasifikasi updraft, instalasi alat gasifikasi pada penelitian ini dapat dilihat pada gambar 3 dan bahan pada penelitian ini menggunakan biomassa sekam padi dan batubara kualitas rendah (soubituminnous) Komposisi campuran bahan antara sekam padi dan batubara adalah sempel A sekam padi 200 gr dan batubara 0 gram, pada sempel B sekam padi 180 gram dan batubara 20 gram, pada sempel C sekam padi 140 gram dan batubara 60 gram dan pada sempel D sekam padi 100 gram dan batubara 100 gram.
1. Thermocontroller
2. Thermocouple
3. Data logger
4. Tungku/furnace
5. Heater
6. Laptop
7. Tabung Elemeyer
8. Flowwmeter
9. Urine Bag

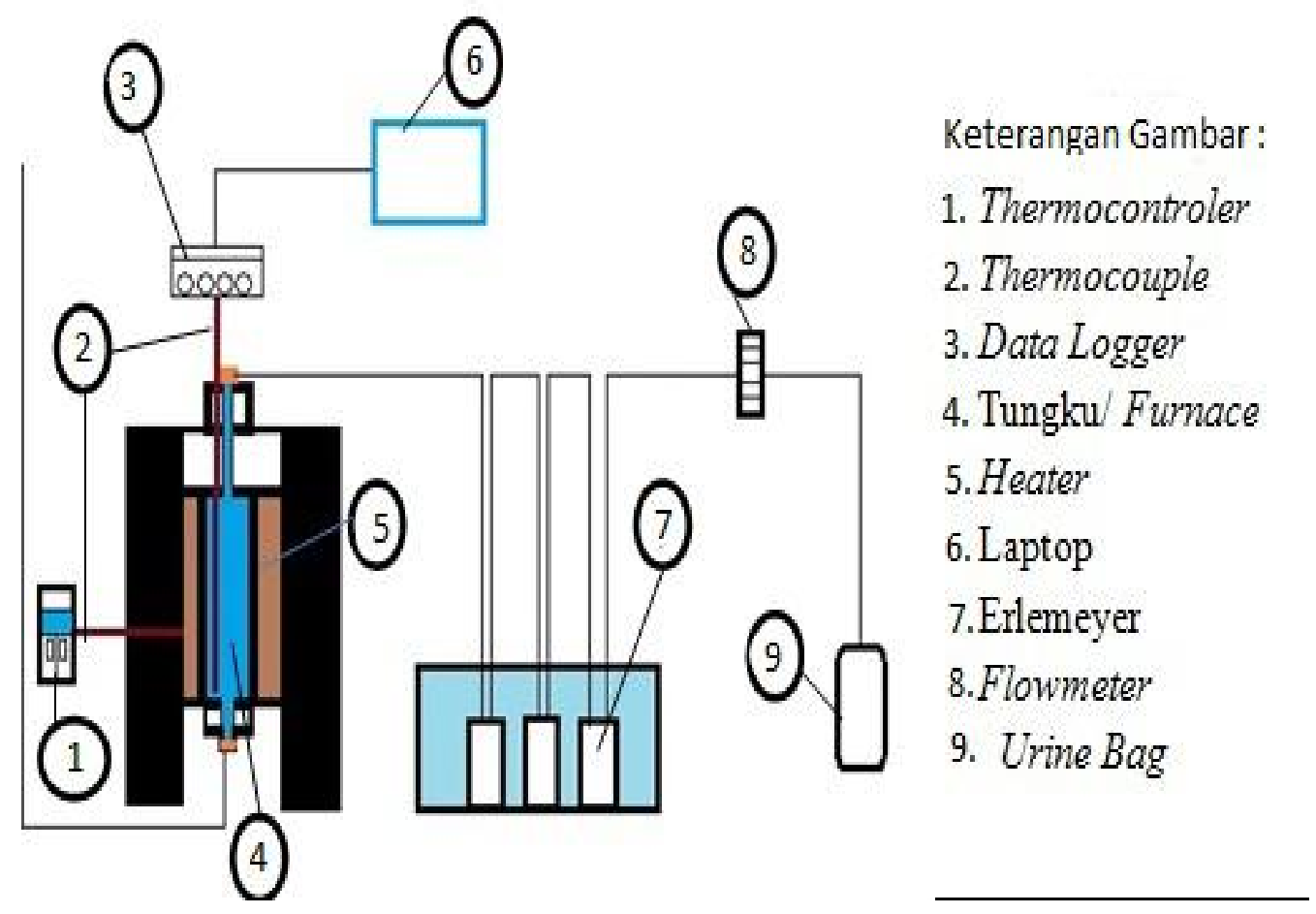

Gambar 3 Instalasi alat gasifikasi 


\section{Tahapan Pengujian}

Campur bahan antara sekam padi dan batubara didalam wadah kemudian aduk merata anatara sekam padi dan batubara, kemudian masukkan bahan ke dalam tungku, sekam padi dan batubara kualitas rendah yang sudah siap kita masukkan ke dalam tungku gasifikasi, kemudian setelah semua intalasi terpasang dengan sempurna maka masukan sekam padi dan batubara kualitas rendah kedalam tunggku gasifikasi, setelah itu tutup rapat bagian atas tungku dan cek kembali apakah ada kebocoran pada tungku. Setelah dipastikan tidak terjadi kebocoran maka hidupkan sakelar pada thermocontroler dan secara beiringan jalankan data logger. Cacatlah temperatur selama jalannya proses gasifikasi dan temperature heater setiap 5 menit dan catat volume gas yang dihasilkan setiap kenaikan $50 \mathrm{~cm}^{3}$. Jika temperatur sudah mencapai $500^{\circ} \mathrm{C}$ jaga temperatur tersebut agar konstan dan pastikan tidak terjadi kebocoran. Kemudian catat total hasil gas, tar dan char yang terbentuk
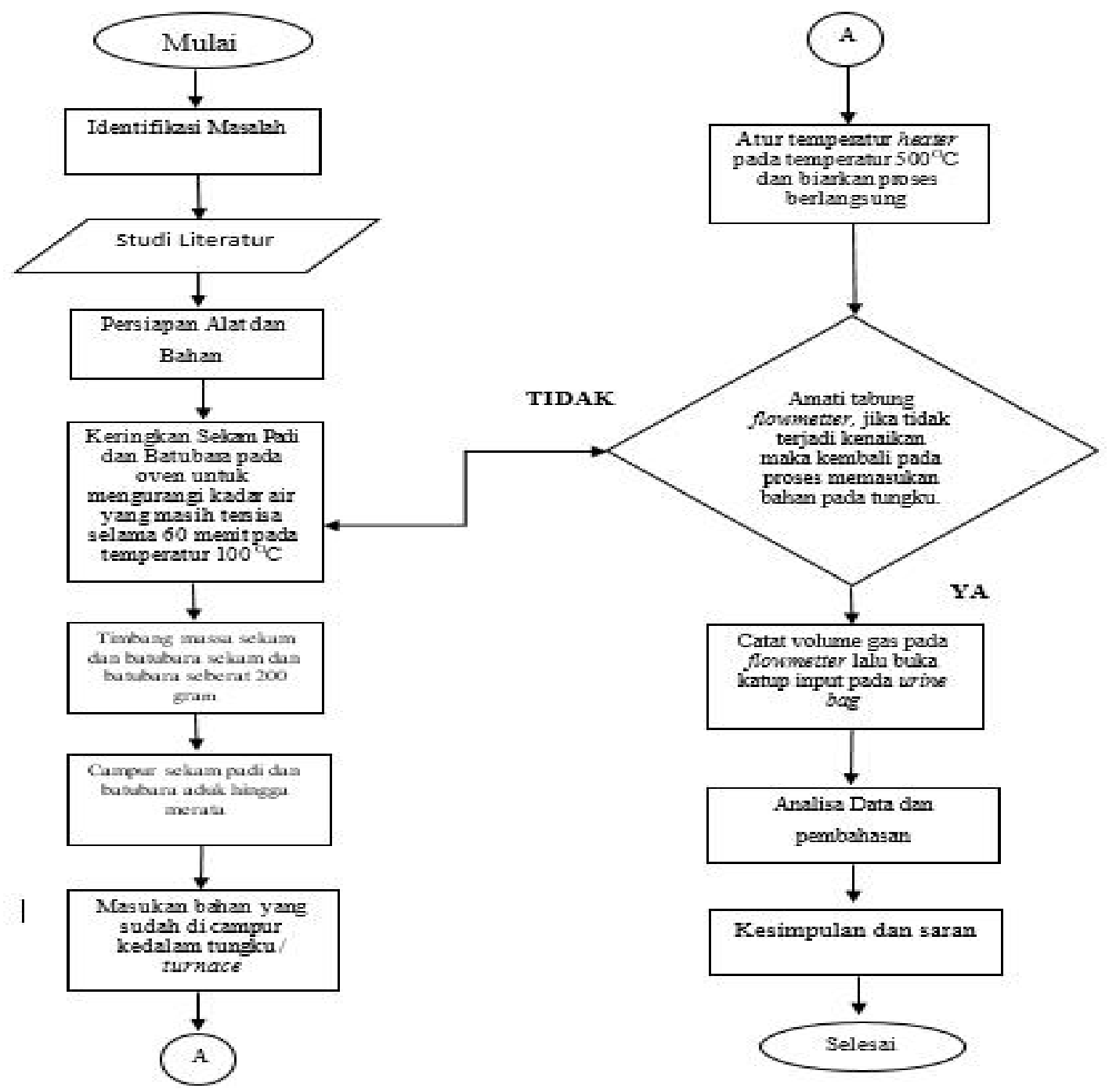

Gambar 4 Diagram Alir Penelitian 


\section{Hasil dan Pembahasan}

Data hasil penelitian yang diambil berupa data laju pemanasan, data hubungan temperatur terhadap waktu, data hasil volume syngas dan data produk sampingan berupa Char (arang) dan Tar. Data hasil penelitian ini akan disajikan dalam bentuk grafik dan table.

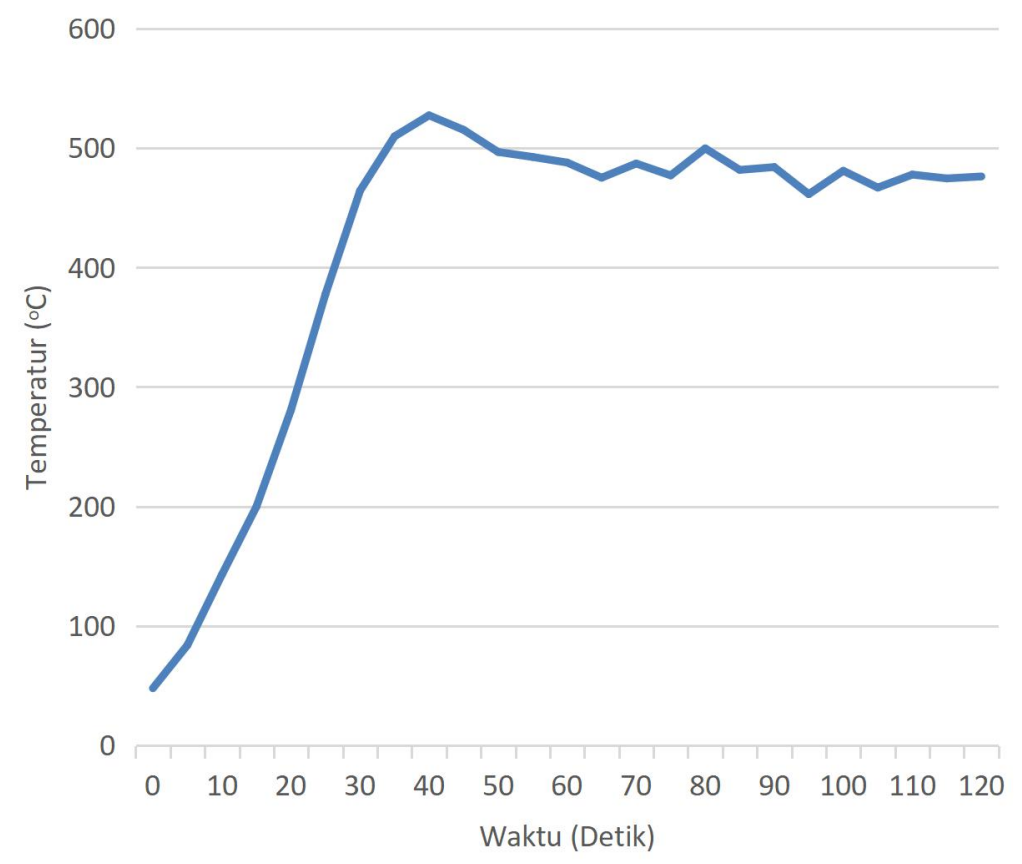

Gambar 5 Grafik hubungan temperatur terhadap waktu pada sekam padi 200 gr dan batubara 0 gr.

Pada gambar 5 menunjukkan grafik hubungan temperatur terhadap waktu, dimana temperatur awal pemanasan $27^{\circ} \mathrm{C}$ kemudian dipanaskan hingga 120 menit. Pada grafik variasi bahan campuran sekam padi $200 \mathrm{gr}$ : batubara 0 gr seiring bertambahnya waktu maka temperatur ikut meningkat dan waktu yang dibutuhkan untuk mencapai temperatur $500^{\circ} \mathrm{C}$ adalah 42 menit. Kemudian temperatur berfluktuasi hingga waktu mencapai 120 menit. 


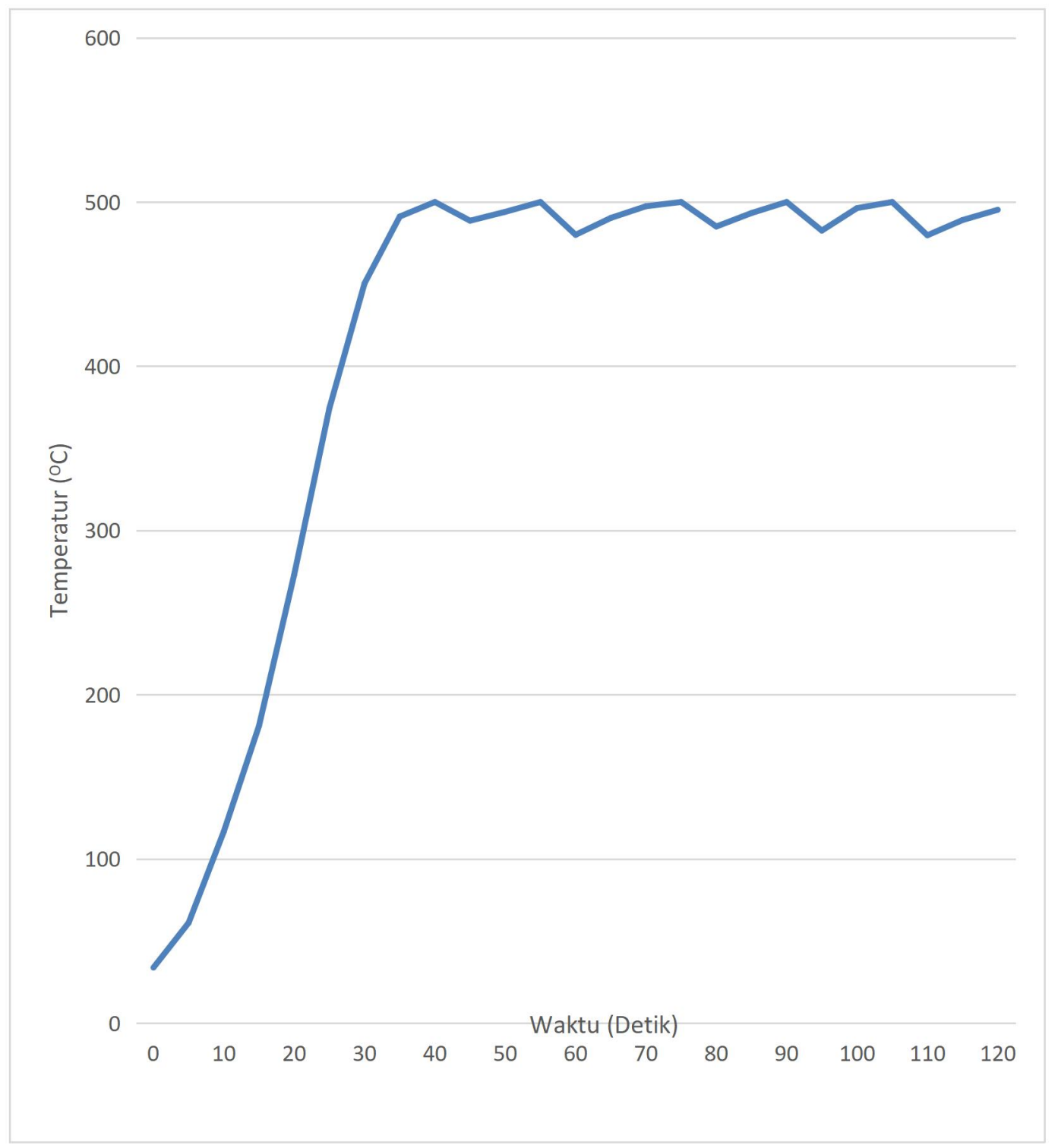

Gambar 6 Grafik hubungan temperatur terhadap waktu pada sekam padi 180 gr dan batubara $20 \mathrm{gr}$

Pada gambar 6 menunjukkan grafik hubungan temperaturterhadap waktu, dimana temperatur awal pemanasan $27^{\circ} \mathrm{C}$ kemudian dipanaskan hingga 120 menit. Pada kurva variasi bahan campuran sekam padi 180 gr : batubara 20 gr seiring bertambahnya waktu maka temperatur ikut meningkat, waktu yang dibutuhkan untuk mencapai temperatur $500^{\circ} \mathrm{C}$ adalah 36 menit. Kemudian temperatur berfluktuasi hingga waktu mencapai 120 menit. 


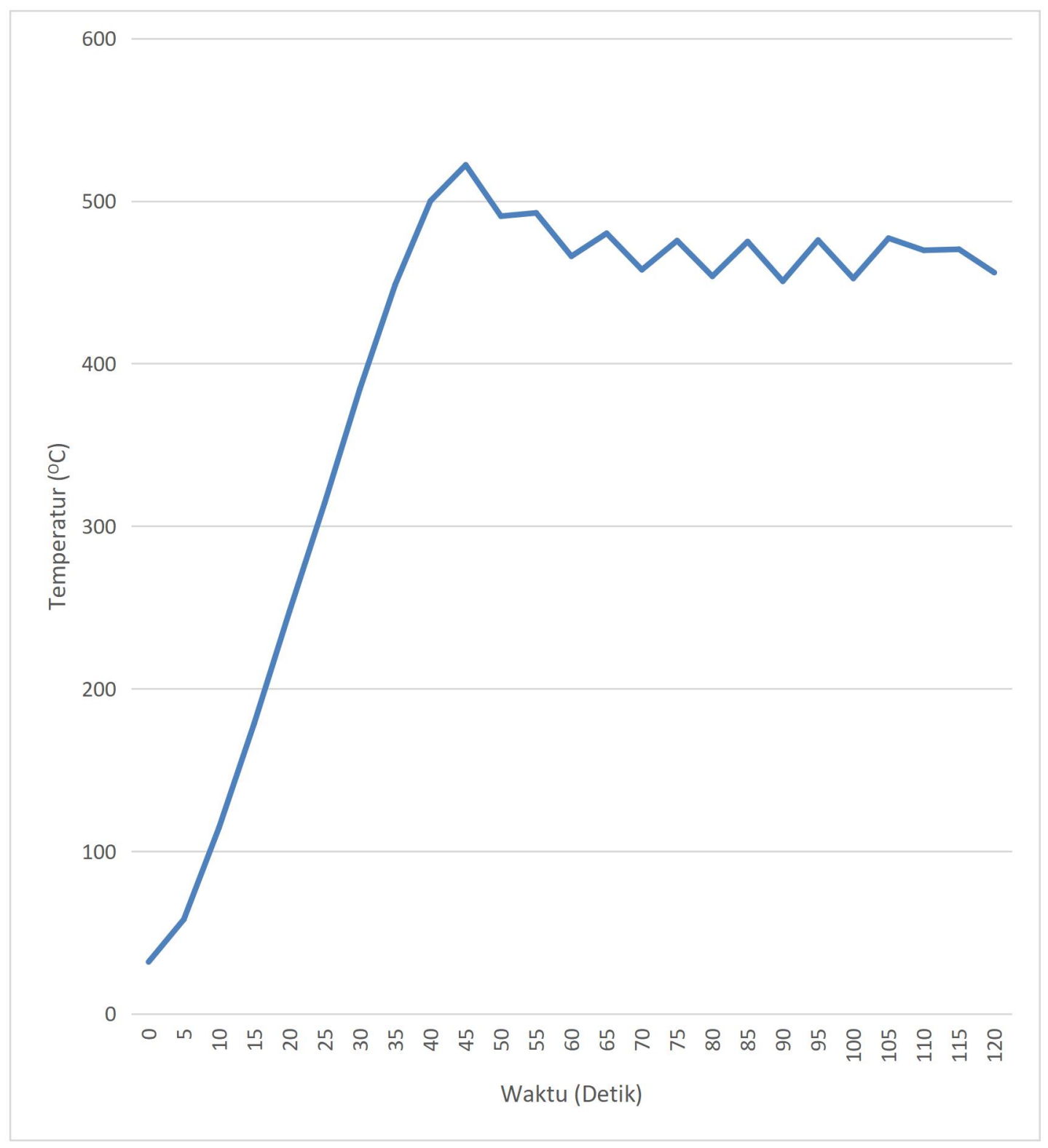

Gambar 7 Grafik hubungan temperatur terhadap waktu pada sekam padi 140 gr dan batubara 60 gr

Pada gambar 7 menunjukkan grafik hubungan temperatur terhadap waktu, dimana temperatur awal pemanasan $27^{\circ} \mathrm{C}$ kemudian dipanaskan hingga 120 menit. Pada grafik variasi bahan campuran sekam padi $140 \mathrm{gr}$ : batubara 60 gr seiring bertambahnya waktu maka temperatur ikut meningkat, waktu yang dibutuhkan untuk mencapai temperatur $500^{\circ} \mathrm{C}$ adalah $39,33^{\circ} \mathrm{C} /$ menit. Kemudian temperatur berfluktuasi hingga waktu mencapai 120 menit. 


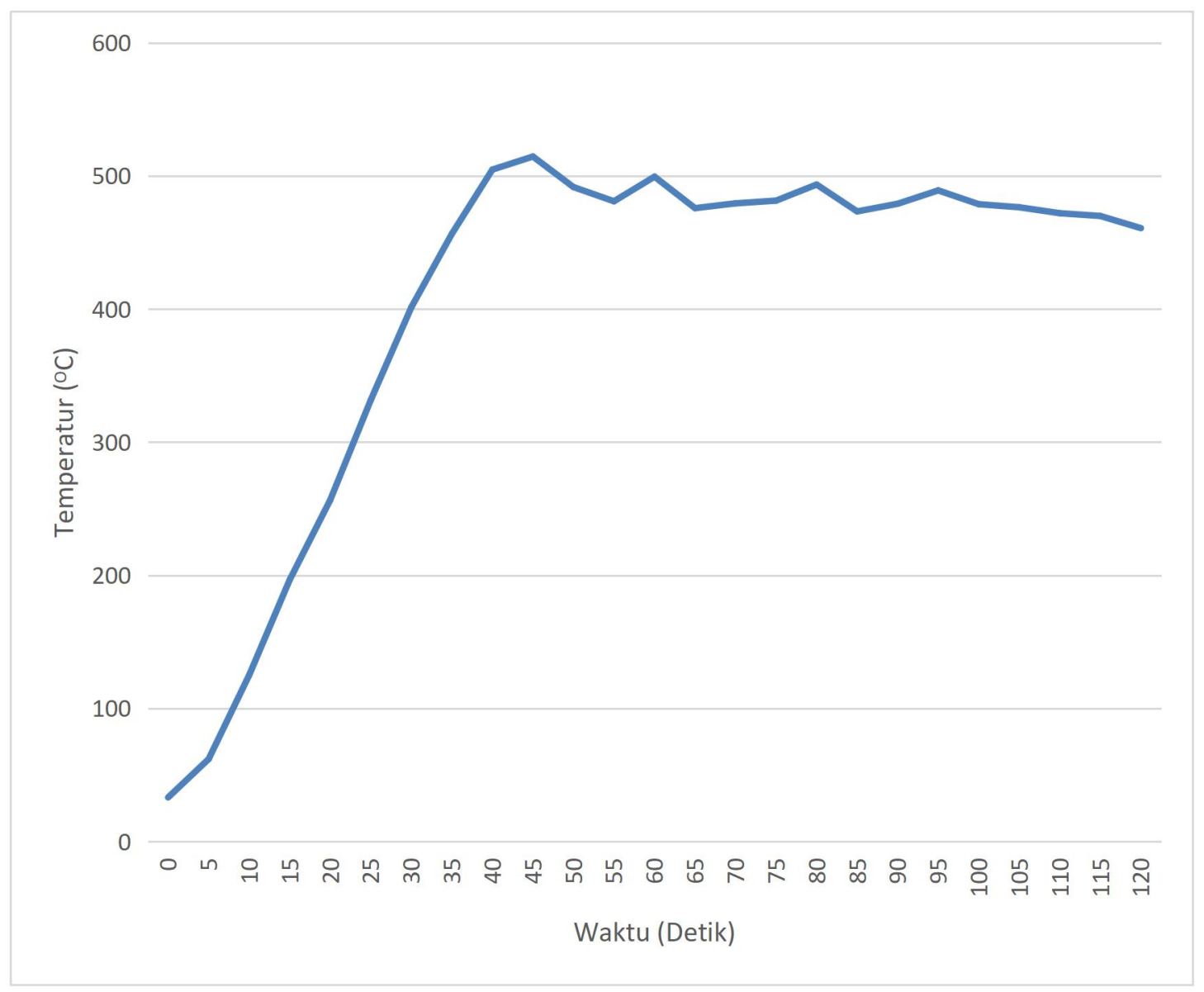

Gambar 8 Grafik hubungan temperatur terhadap waktu pada sekam padi 100 gr dan batubara 100 gr.

Pada gambar 8 menunjukkan grafik hubungan temperatur terhadap waktu, dimana temperatur awal pemanasan $27^{\circ} \mathrm{C}$ kemudian dipanaskan hingga 120 menit. Pada grafik variasi bahan campuran sekam padi 100 gr : batubara 100 gr seiring bertambahnya waktu maka temperatur ikut meningkat, waktu yang dibutuhkan untuk mencapai temperatur $500^{\circ} \mathrm{C}$ adalah $11,82^{\circ} \mathrm{C} /$ menit. Kemudian temperatur berfluktuasi hingga waktu mencapai 120 menit. 


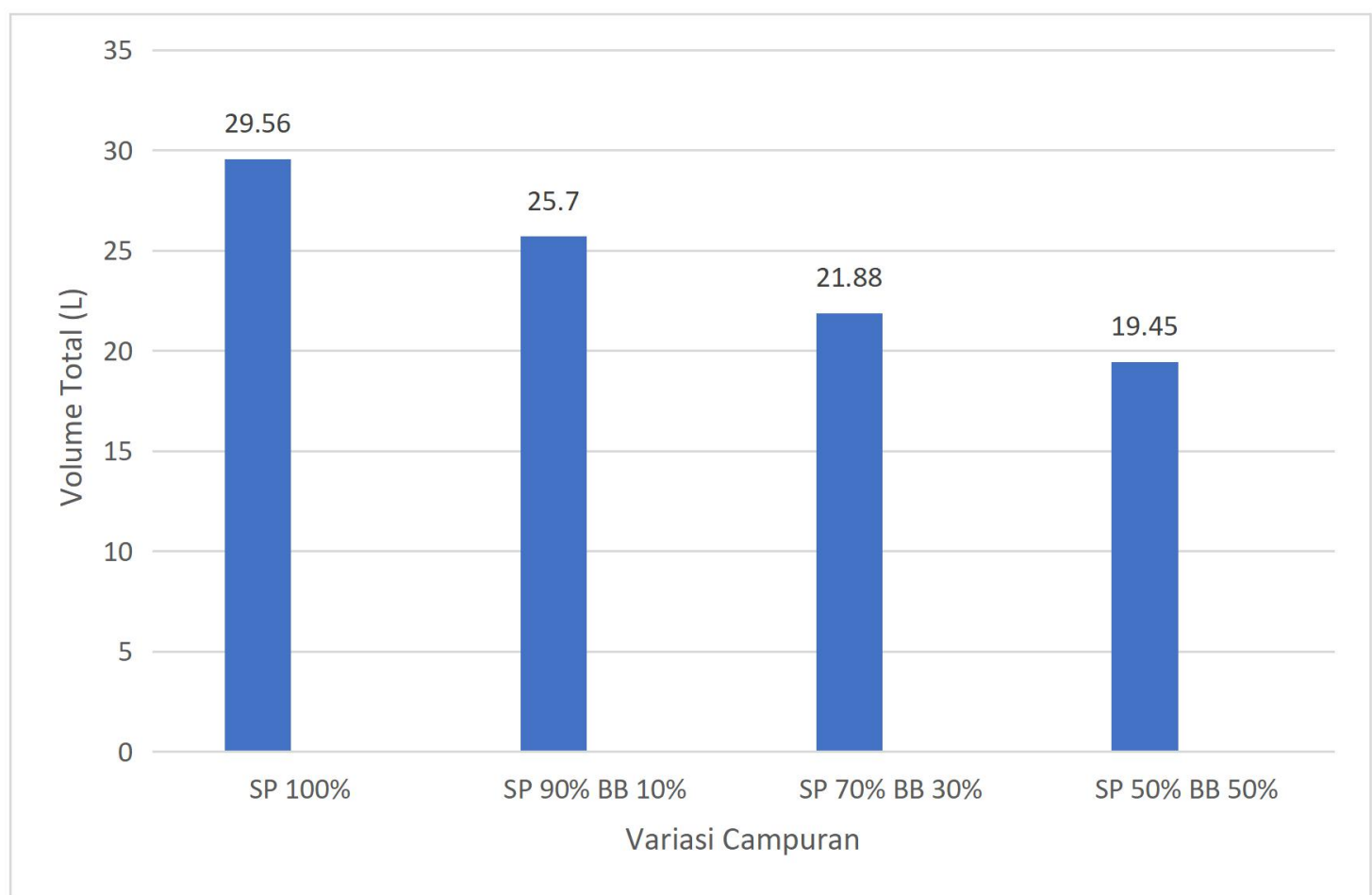

Gambar 9 Grafik volume gas sekam padi dan batubara pada semua variabel.

Pada gambar 9 menunjukan volume gas yang dihasilkan lebih besar pada sekam padi 200 gr : batubara 0 gr sebesar 29,56 L, pada sekam padi 180 gr : batubara 20 gr sebesar 25,7 L, pada sekam padi 140 gr : batubara 60 gr sebesar $21.88 \mathrm{~L}$, pada sekam padi 100 gr : batubara 100 gr sebesar $19.45 \mathrm{~L}$.

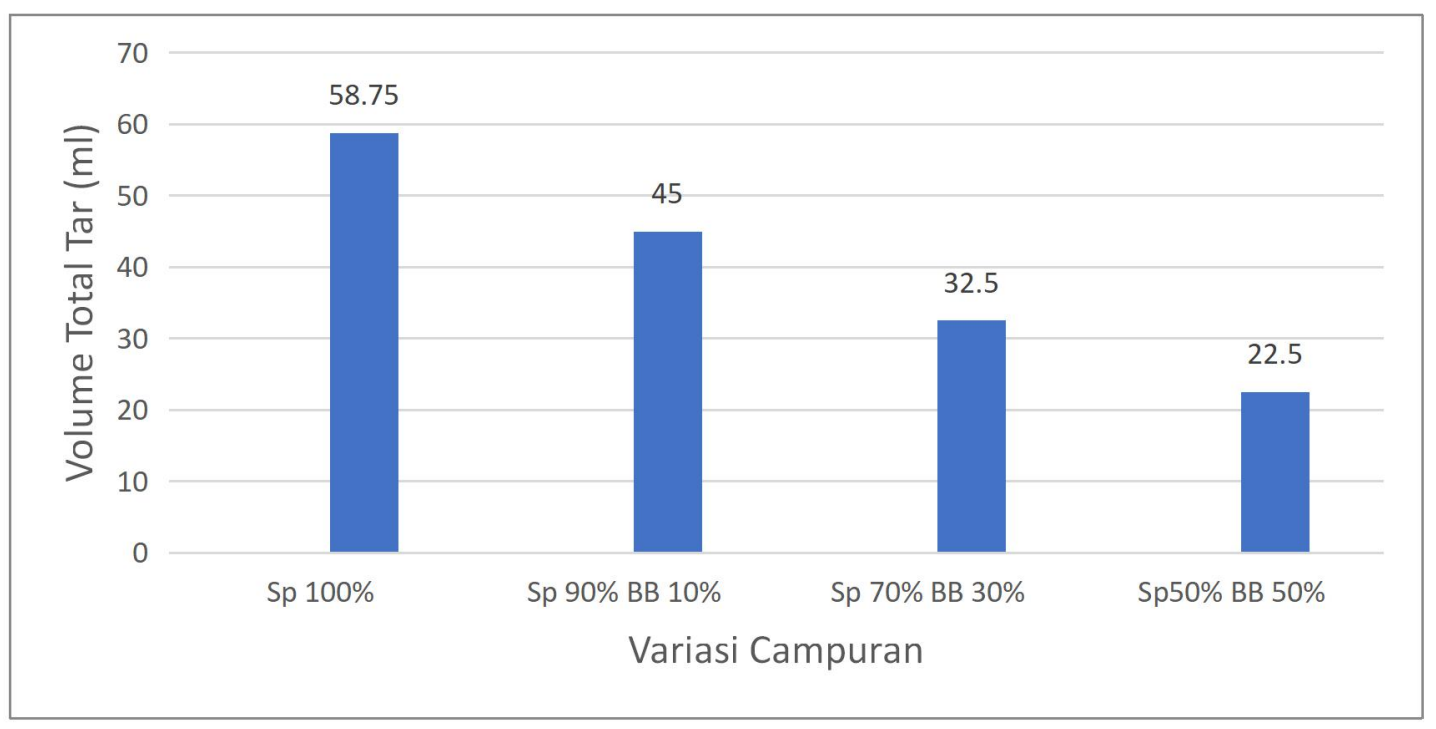

Gambar 10 Grafik hasil Tar sekam padi dan batubara pada semua variabel 


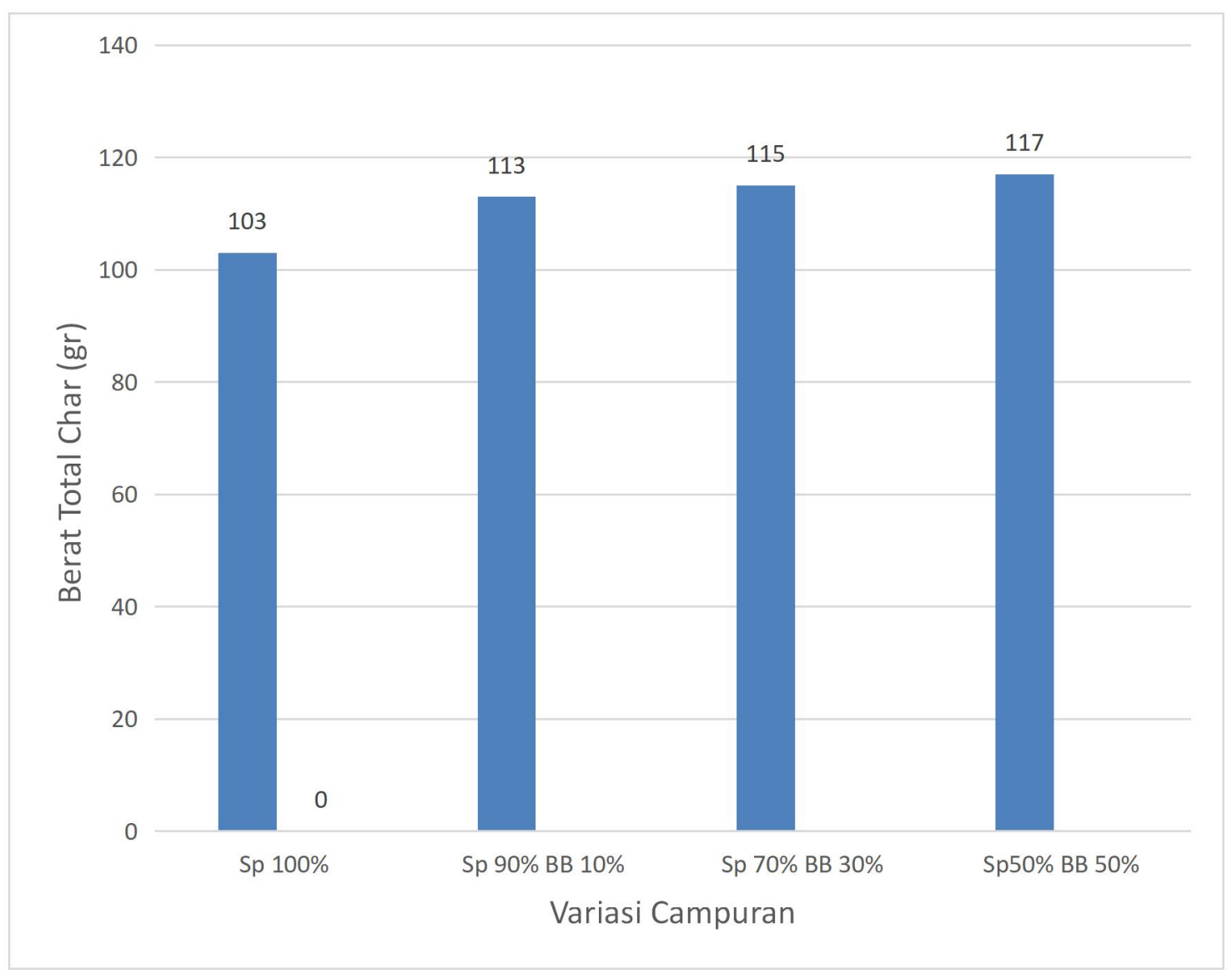

Gambar 11 Grafik hasil Char sekam padi dan batubara pada semua variabel

Pada gambar 10 Grafik hasil Tar sekam padi dan batubara pada semua variabel dan gambar 11 Grafik hasil Char sekam padi semua variabel merupakan produk sampingan yang dihasilkan dari proses gasifikasi. Tar paling besar dihasilkan pada sempel SP 200 gr : BB 0 gr sebanyak 58,75 ml dan Char yang dihasilkan paling besar adalah pada sempel SP 140 : BB 60 gr sebanyak 117 gram.

\section{KESIMPULAN}

Berdasarkan pembahasan dan analisa data dari pengujuan gasifikasi sekam padi dan batubara kualitas rendah dengan variasi sempel SP 200 gr : BB 0 gr, SP 180 gr BB 20 gr, SP 140 gr : BB 60 gr dan SP 100 gr BB 100 gr dapat diambil kesimpulan sebagai berikut:

1. Total hasil syngas yang didapatkan pada proses gasifikasi updraft sekam padi dan batubara kualitas rendah yaitu sebanyak 96,62 L. Volume terbanyak pada sempel SP 200 gr : BB 0 gr sebesar sebesar 29,56 L, pada sempel SP 180 gr : BB 20 gr sebesar 25,7 L, pada SP 140 gr : BB 60 gr sebesar 21.88 L dan volume paling sedikit pada SP 100 gr : BB 100 gr sebesar $19.45 \mathrm{~L}$.

2. Hasil dari produk sampingan gasifikasi updraft sekam padi dan batubara kualitas rendah didapatkan hasil Tar paling tinggi pada sempel SP 200 gr : BB 0 gr sebanyak 58,75 ml, pada sempel SP 180 gr : BB 20 gr dihasilkan sebanyak 45 ml, pada sempel SP 140 gr BB 60 gr dihasilkan 32,5 ml dan pada sempel SP 100 gr : BB 100 gr dihasilkan sebanyak 22,5 $\mathrm{ml}$. 


\section{DAFTAR PUSTAKA}

Adbul Ghofar, Rudy Sitorus, Erbert Ferdy Destian. 2017. Simulation And Estimation In Energy Need For Gasifier System Using Coal From South Sumatra And South Kalimantan As Raw Material. Pusat Teknologi Sumberdaya Energi Dan Indutri Kimia.

Adimas Rangga j. 2017. Pengaruh Katalis Bentonit Terhadap Hasil Gasifikasi Updraft Cangkang Kelapa Sawit Pada Temperatur $550{ }^{\circ} \mathrm{C}$, $650{ }^{\circ} \mathrm{C}$, $750{ }^{\circ} \mathrm{C}$. Skripsi. Tidak Dipublikasikan. Universitas Brawijaya.

Badan Pusat Statistik Provinsi Kalimantan Selatan. 2016. Survei Pertanian Produksi Tanaman Padi dan Palawija Kal-Sel. Banjarmasin. CV. Karya Bintang Muslim.

Basu, Prabir. 2010. Biomass Gasification and Pyrolisis Practical Design and Theory.Elsevier.

Eni .2015. Potensi Berbagai Bahan Organik Rawa Sebagai Sumber Biochar. Balai Besar Sumber Daya Lahan Pertanian. Kampus Penelitian Pertanian Cimanggu, Jawa Barat.

Irwandy, Arif. 2010. Batubara Indonesia. Jakarta. PT. Gramedia pustaka Utama.

Suliono, Felix donius, Yusup Nur Rahmat. 2017. Unjuk Kerja Reaktor Gasifikasi Sekam Padi Sebagai Alat Pembuat Gas Pengganti Elpiji Pada Rumah Tangga. Seminar Nasional Teknologi Dan Rekayasa. Politeknik Negeri Indramayu

Susanto, H. 2005. Pengujian PLTD-Gasifikasi Sekam Padi 100 kW di Haurgeulis, Indramayu. Program Studi Teknik Kimia FTI-ITB.

Syinya Yokoyama, Matsumura. 2008. Asian Biomass Handbook. The Japan Institute Of Energy. 